УДК 316.334.2(06)

10.17213/2075-2067-2021-1-22-31

\title{
ЭКОНОМИЧЕСКОЕ ПОВЕДЕНИЕ И СОЦИАЛЬНО-ЭКОНОМИЧЕСКИЕ ПРАКТИКИ НАСЕЛЕНИЯ СРЕДНЕГО РОССИЙСКОГО ГОРОДА: ОПЫТ СОЦИОЛОГИЧЕСКИХ ИССЛЕДОВАНИЙ
}

\author{
(C) 2021 г. С. В. Барсукова, С. М. Барсуков, О. А. Ткачева \\ Шахтинский автодорожный институт (филиал), \\ Южно-Российский государственный политехнический университет (НПИ) \\ имени М. И. Платова, г. Шахты, Россия
}

Целью исследования является анализ сочиальных проблем и выяснение особенностей экономического поведения работающего населения среднего российского города в условиях трансформационных процессов в современном российском обществе на фоне распространения коронавирусной инфекции.

Методологической основой исследования являются научные разработки, теоретические и практические предложения, представленные отечественными и зарубежными исследователями социологической науки, которые содержатся в работах по изучению проблем экономического поведения работающего населения России (М. К. Горшков, М. В. Шульгин, Н. В. Дулина, В. Ю. Бочаров, Т. В. Гаврилюк и др.), в том числе идеи и представления, разработанные в рамках общей теории систем и структурно-функционального подхода.

Результаты исследования. $B$ статье рассматривается экономическое поведение и социально-экономические практики населения России с учетом условий распространения коронавирусной инфекиии, приведшей к снижению потребительского спроса и в иелом ВВП как в России, так и в других странах. Авторами статьи представлены результаты российских сочиилогических исследований экономического поведения населения, а также данные собственного соииологического исследования, полученные методом анкетного опроса работающего населения города Шахты. Полученные результаты демонстрируют различные модели поведения россиян в экономической сфере, при этом традиционные модели экономического поведения населения существенным образом видоизменяются в условиях экономического кризиса и распространения коронавирусной инфекции, приобретая новые черты и особенности.

Перспективу исследования составляет дальнейший социологический анализ экономического поведения различных сощиильных групп населения как в условиях экономических кризисов, так и распространения коронавирусной инфекции.

Ключевые слова: экономическое поведение; факторы, модели экономического поведения; социальные трансформачии; коронавирусная инфекция; COVID-19; валовой внутренний продукт; ВВП. 


\title{
ECONOMIC BEHAVIOUR AND SOCIAL AND ECONOMIC PRACTICIANS OF THE POPULATION OF THE AVERAGE RUSSIAN CITY: EXPERIENCE OF SOCIOLOGICAL RESEARCHES
}

\author{
(C) 2021 S. V. Barsukova, S. M. Barsukov, O. A. Tkacheva
}

\section{Shakhty Road Institute (branch), Platov South Russian State Polytechnic University (NPI), Shakhty, Russia}

Research objective is the analysis of social problems and clarification offeatures of economic behavior of the working population of the average Russian city in the conditions of transformational processes in modern Russian society against the background of spread of a koronavirusny infection.

Methodological basis of a research are the scientific developments, theoretical and practical offers submitted by domestic and foreign researchers of sociological science who contain in works on studying of problems of economic behavior of the working population of Russia (M. K. Gorshkov, M.V. Shulgin, N.V. Dulina, V. Yu. Coopers, T.V. Gavrilyuk, etc.), including, the ideas and representations developed within the general theory of systems and structurally functional approach.

Results of a research. In article the economic behavior and social and economic practicians of the population of Russia taking into account conditions of spread of the koronavirusny infection which led to decrease in consumer demand and in the whole GDP both in Russia and in other countries is considered. Authors of article presented results of the Russian sociological researches of economic behavior of the population and also the data of own sociological research received by method of questionnaire of the working population of the city of Shakhty. The received results show various behavior models of Russians in the economic sphere, at the same time traditional models of economic behavior of the population essentially change in the conditions of an economic crisis and spread of a koronavirusny infection, gaining new lines and features.

The prospect of a research is made by the further sociological analysis of economic behavior of various social groups of the population as in the conditions of economic crises, and spread of a koronavirusny infection.

Key words: economic behavior; factors, models of economic behavior; social transformations; koronavirusny infection; COVID-19; gross domestic product; GDP.

Введение. Актуальность социологических исследований экономического поведения населения России в настоящее время является особо значимой и перспективной по ряду важных причин, связанных с особой ролью человеческого фактора в экономических процессах, социально-экономическим неравенством в России и невысоким уровнем жизни, а также с распространением новой коронавирусной инфекции, что непосредственным образом сказывается на развитии мировой и российской экономики и как следствие - экономическом поведении населения в реальной экономической практике. Экономическое поведение реализуется в разнообразных формах, детерминируется различными социальными институтами, поэтому изучение проблем экономического поведения и социально-экономических практик населения выступает актуальной задачей многих наук (в первую очередь экономической и социологической), что подтверждается наличием многочисленных исследований, сложившимися определенными традициями, подходами и школами.

Своеобразие социологического анализа экономической жизни заключается в поведен- 
ческом подходе, а весомый вклад в изучение экономического поведения населения внесли такие исследователи, как М. Вебер, Э. Дюркгейм, Г. Зиммель, Т. Парсонс, Н. Смелзер, П.А. Сорокин и многие другие. В современной отечественной социологии проблема экономического поведения - в центре внимания М.А. Бухараевой, В.И. Верховина, 3.Т. Голенковой, С.Л. Еременко, Т.И. Заславской, А. А. Земцова, М. А. Козловой, В.В. Радаева, Н. Римашевской, Р.В. Рывкиной, Г.А. Силласте и многих других авторов [1-4]. Анализу теоретических, методологических и концептуальных подходов к экономическому поведению, осмыслению категории, сущности и особенности экономического поведения населения посвящены статьи Г.В. Белеховой, Ю.И. Бушеневой и др. [5-6]. Анализ научной литературы показывает, что изучение социальных проблем формирования экономического поведения населения в России в настоящее время идет достаточно активно, рассматривается в большом многообразии определений.

Цель и предмет исследования. Целью исследования в настоящей статье является анализ социальных проблем экономического поведения работающего населения среднего российского города в современных условиях, что определяет ее предмет: на основе данных социологических исследований выяснение особенностей экономического поведения населения в условиях трансформационных процессов в современном российском обществе на фоне распространения коронавирусной инфекции.

Методология исследования. Методологической основой исследования являются научные разработки, теоретические и практические предложения, представленные отечественными и зарубежными исследователями социологической науки, которые содержатся в работах по изучению проблем экономического поведения работающего населения России, в том числе идеи и представления, разработанные в рамках общей теории систем и структурно-функционального подхода. В ходе исследования применялись методы: анкетного опроса, анализ документов, сравнительный, статистический и интерпретации социологической информации, вторичный анализ социологических данных.

В социологической энциклопедии экономическое поведение трактуется как «поведение, связанное с перебором экономических альтернатив с целью рационального выбора, т.е. выбора, в котором минимизируются издержки и максимизируется чистая выгода. Предпосылками экономического поведения выступают экономическое сознание, экономическое мышление, экономические интересы, социальные стереотипы. При этом каждый феномен по-своему формирует тот или иной тип экономического поведения» [7]. В социологии при изучении экономического поведения акцентируется внимание на факторах, институтах и социальных субъектах, которые имеют экономические интересы. По мнению В.И. Верховина, в социологической науке отсутствует единая классификация видов экономического поведения, тем не менее, ученый выделяет следующие основные виды: производственное, обменное, дистрибутивное (распределительное) и потребительское поведение, которые часто не проявляются в чистом виде. Автор также выделяет ряд моделей и разновидностей экономического поведения: монетарные, хозяйственные, редистрибутивные, покупательские, сбытовые, коммерческие, маркетинговые, посреднические, конъюнктурные, игровые, предпринимательские, спекулятивные, ненормативные и др. Экономическое поведение можно классифицировать также по демографическим, территориальным, отраслевым, профессионально-квалификационным и другим характеристикам.

Научные результаты исследований. Процесс распространения коронавирусной инфекции, получившей официальное название COVID-19 (на 01.12.2020 г. количество заболевших в мире - около 63,57 млн. человек, количество умерших - 1,47 млн.), серьезным образом сказывается на экономическом поведении населения, находит свое отражение в мировой экономике, российская экономика также сталкивается с рядом существенных финансово-экономических проблем. Еще в начале 2020 г. многие эксперты отмечали и отмечают отрицательное воздействие пандемии, что непосредствен- 
ным образом сказывается на уровне валового внутреннего продукта (ВВП) многих стран и снижении цен на энергоносители на мировом рынке. Данные факторы значимы для России, так как экспорт нефти и нефтепродуктов из Российской Федерации был и остается важнейшей статьей российского экспорта (экспорт нефти и нефтепродуктов из Российской Федерации в среднем составил от 40 до $50 \%$ общего объема экспорта: в товарной структуре экспорта нефть и нефтепродукты в 2016 г. составили 41,6\%, в 2018 г. - 46,1\%, в 2019 г. - 44,4\%) [8].

В первом полугодии 2020 г. пандемия коронавируса нанесла серьезный урон экономикам практически всех стран. В I квартале среди экономик G20 наибольший спад ВBП относительно предыдущего года имели страны, которые ранее других ввели режимы самоизоляции: Китай - 6,8\%, Франция - 5,7\% и Италия - 5,6\%. Во II квартале: США 9,0\%, падение ВВП стран ЕС достигло 13,9\%, а стран еврозоны - 14,8 \%, что является крупнейшим снижением с 1995 г. [9].

В течение 2020 г. оценки снижения ВВП как в России, так и в других странах неоднократно уточнялись и пересматривались. Еще в начале года ожидалось, что «уровень валового внутреннего продукта (ВВП) России под влиянием пандемии может снизиться не менее, чем на 10-20\%» [10, с. 260]. По данным Росстата, по итогам I квартала рост ВВП в России составил $1,6 \%$, а с введением режима самоизоляции во втором квартале 2020 г. произошло снижение ВВП, что составило $8,0 \%$ (это оказалось меньше оценок Минэкономразвития России и прогнозов большинства аналитиков), поэтому «за первое полугодие российский ВВП снизился на 3,4\% г/г» [11]. В III квартале ВВП России более чем вдвое замедлил темпы падения, он снизился всего лишь на 3,6\% после спада на $8 \%$ во II квартале. Ограничить спад в экономике позволили меры поддержки бизнеса и населения, которые были приняты Правительством Российской Федерации и Банком России. По прогнозам экспертов МВФ, в 2020 г. ожидается сокращение ВВП на 4\%, а в 2021 г. рост составит около 2,5\% при условии постепенного снижения эпидемических рисков. Наибольший спад наблюдался в России в секторах экономики, ориентированных на потребительский спрос. Пандемический кризис привел к сокращению заработков россиян, что сказывается на их экономическом поведении (по данным Росстата, реальные располагаемые денежные доходы населения во втором квартале 2020 г. снизились на $8,4 \%$ в годовом выражении). Между тем ожидается, что во второй половине 2020 года в восстановлении роста ВВП сыграет свою роль именно увеличение потребительского спроса.

Инновационный характер экономики в мире приводит к использованию новых технологий: интернет-магазины, технологии дистанционного банковского обслуживания клиентов с доступом к их счетам и операциям в сети Интернет, что стало особо актуально в условиях коронавирусной инфекции. Современная глобализирующаяся экономика приобретает все больший сетевой и информационный характер, поэтому необходимо социологическое изучение процессов экономического поведения россиян в условиях глобализации [12].

Результаты многочисленных социологических исследований поведения россиян в экономической сфере демонстрируют различные образцы (модели) их поведения. В социологии экономическое поведение традиционно изучается в контексте социальных трансформаций. Например, Институт социологии РАН под руководством М.К. Горшкова изучает экономическое поведение населения в динамике в зависимости от тенденций экономического развития общества, т.е. поведение изменяется под влиянием социальных трансформаций. В исследовательской литературе изучается экономическое поведение различных социальных групп (С.А. Цветков и Ж.А. Жилина, С.Н. Залесская). Наблюдения и исследования показывают, что большая часть покупателей чаще всего непоследовательны, зачастую нелогичны и переходят от потребления одной торговой марки к другой. Достаточно много покупок делается под воздействием моды, субкультуры, в зависимости от профессии. Например, М.В. Шульгин изучил особенности поведения студентов Иркутского государственного технического университета на рынке кофе и пива. Автор отмечает, что решение о покупке студенты принимают чаще либо в домашней обстановке (36\%), либо непосредственно в магазине (37\%). При этом ус- 
тановлен достаточно большой сегмент лиц, принимающих решение в кругу друзей и однокурсников (25\%). Анализируя публикации о кредитном поведении, размещенные в базе РИНЦ, Н.В. Дулина делает вывод о слабой разработанности данной тематики не только по отдельным социально-демографическим группам, но и в целом по населению. Ею проведено социологическое исследование в г. Волгограде среди студентов вузов на рубеже 2017-2018 гг., в результате чего автор приходит к заключению, что студенты ориентированы на сбережение; в сложной ситуации у них сильна установка на экономию финансов, а не решение проблем посредством заимствования; проявляют готовность повышать свою финансовую грамотность, выстраивать свою финансовую стратегию и не все готовы рискнуть; они «негативно относятся к фактам спонтанных/ненужных покупок» [13, с. 85].

Для российской банковской системы сбережения населения являются весьма важным источником финансовых ресурсов, при этом выявляется такая закономерность экономического поведения, как «объемы вкладов населения растут в декабре, в январе практически всегда происходит изъятие населением своих денежных средств из банков» $[14$, с. 1003]. По данным мониторингового исследования ВЦИОМ, посвященного изучению потребительского и кредитного доверия россиян (опрос проведен 25 октября 2020 г.), лишь $23 \%$ россиян посчитали октябрь удачным для совершения крупных покупок (62\% придерживаются обратного мнения); 13\% решили, что это время, удачное для кредитования. Россияне придерживаются сберегательного поведения (70\% отмечают, что необходимо тратить по минимуму, оставляя на будущее). $65 \%$ россиян имеют сбережения (61\% хранят в рублях, $8 \%$ в долларах и $6 \%$ в евро). $35 \%$ отметили, что у них нет сбережений [15]. Данные социологических опросов свидетельствуют о крайне неравномерном распределении сбережений среди населения. В 2018 г. на территории Уральского федерального округа В.Ю. Бочаровым и Т.В. Гаврилюком было проведено социологическое исследование среди рабочей молодежи, более половины опрошенных отметили, что не имеют возможности делать какие-либо накопления. Авторами было сконструировано три модели экономического поведения рабочей молодежи: «терпеливое молчание», «адаптивное приспособление», «активное действие» [16]. Из-за распространения коронавирусной инфекции на сберегательную модель поведения переходит и средний класс.

С ростом социальной значимости Интернета традиционные модели экономического поведения населения существенным образом видоизменяются, особенно в условиях распространения коронавирусной инфекции, приобретают новые, ранее неизвестные черты и особенности. Сегодня проникновение Интернета среди населения достигло 75\% и покрывает всю Россию. В пространстве глобальной сети трансформируются традиционные торговые площадки, где индивиды реализуют различные стратегии экономического поведения. Через сайты интернет-магазинов потребитель получает перед покупкой информацию о товаре, включая отзывы на него, имеет возможность сравнивать цены. Объемы интернет-торговли постоянно растут, особенно они стали актуальны во время пандемии COVID-19, и все чаще встречаются модели бизнеса, которые осуществляют продажу только через Интернет. Более того, с 01.01.2021 г. вступает в силу Федеральный закон от 8 декабря 2020 г. №407-Ф3 «О внесении изменений в Трудовой Кодекс Российской Федерации в части регулирования дистанционной (удаленной) работы и временного перевода работника на дистанционную (удаленную) работу по инициативе работодателя в исключительных случаях». Предусматриваются постоянный, временный (до 6 месяцев) и комбинированный режимы дистанционной работы работников вне места нахождения работодателя и стационарного рабочего места.

Ситуация экономического кризиса, ставшая частью повседневной реальности россиян, определенным образом отражается на их социально-экономическом поведении. С целью исследования характера экономической активности и реального экономического поведения работающего населения среднего российского города нами было проведено социологическое исследование методом анкетного опроса среди работающего населения города Шахты - 47,83\% респонден- 
тов женского пола и 52,17\% мужского пола. $51,59 \%$ респондентов оценили свое материальное положение как «среднее». Выяснилось, что свыше половины респондентов (57,2\%) совершают закупки продуктов практически каждый день, 22,6\% делают покупки 2-3 раза в неделю. Практика закупки продуктов на неделю распространена среди десятой части респондентов (11,2\%), и лишь 3,4\% респондентов покупают продукты реже, чем раз в неделю. При этом женщины покупки делают чаще мужчин. Если оборот розничной торговли в январе 2020 г. вырос на 2,7\% (в сопоставимых ценах) к январю 2019 г., то уже в июне 2020 г., по данным Росстата, составил 2623,5 млрд. рублей или 92,3\% (в сопоставимых ценах) к уровню соответствующего периода предыдущего года, т. е. сократился на 7,7\%, что свидетельствует об изменении экономического поведения граждан.

По данным нашего опроса, повседневные покупки большинство опрошенных $(81,3 \%)$ предпочитают делать в близко расположенных супермаркетах («Пятерочка», «Магнит»), а также в торговых точках другого типа: на рынках или в близко расположенном продуктовом магазине. Гипермаркет («Лента», «Магнит») в качестве предпочтительных мест покупок назвали 16,7\% опрошенных. В основе выбора покупателями той или иной торговой точки респондентами указывались такие факторы, как «удобное месторасположение магазина рядом с домом» - 87,5\% ответов, «уровень цен в торговой точке»$77,1 \%$, а также «качество товара» $(60,4 \%)$ и «широта ассортимента» - 47,9\%. Важными факторами также выступают наличие парковки, система скидок. Когда возникают трудности в финансовом положении, 33,7\% респондентов экономят, но в долг не берут. Такой тип поведения занял первое место в ответах респондентов. $18,1 \%$ респондентов предпочитают брать деньги в долг у родственников, друзей или знакомых.

Важной составляющей экономического поведения населения является кредитное поведение. По результатам нашего исследования, каждый пятый респондент брал деньги в кредит, и в дальнейшем респонденты не исключают возможности брать ссуду у банка в сложных финансовых ситуациях, причем женщин, настроенных на кредит, больше, чем мужчин.

Интернет-торговля - это динамично развивающаяся во всем мире отрасль, в том числе и в России. Электронную торговлю принято классифицировать по составу ее участников на ряд направлений: бизнес бизнес (В2В), бизнес — потребитель (В2С), потребитель - потребитель (С2С или Р2Р). Рост онлайн-рынка С2С в России за последние два года составил 92,5\% и достиг 568 млрд. руб. в 2018 г. Количество продавцов превысило количество покупателей: 14 млн. против 12 млн. В настоящее время самой популярной формой электронной торговли является сектор В2С. Современные интернеттехнологии позволяют человеку быстро и без посредников получить нужную информацию о товаре, продать или купить необходимое, заказать доставку на дом или забрать покупку в пункте выдачи.

На сайтах в сети Интернет можно найти множество рейтинговых оценок лучшим торговым площадкам и интернет-магазинам в России. Например, по мнению редакции сайта «GadgetOK.ru», в десятку лучших интернет-магазинов входят: 1. Wildberries.ru, 2. Aliexpress.com, 3. Ozon.ru, 4. Lamoda.ru, 5. Mvideo.ru (М-видео), 6. Svyaznoy.ru (Связной), 7. Exist.ru, 8.Kupivip.ru, 9. Ikea.ru, 10. Eldorado.ru (Эльдорадо). Респондентами нашего исследования были названы: Wildberries, Ozon, Aliexpress, М-видео, Эльдорадо, Кари. Среди товаров, которые респонденты заказывали через Интернет, были одежда, обувь, товары для детей, товары личной гигиены, товары для дома (техника, инструменты) и др.

В России из-за практического отсутствия официальных статистических данных, касающихся интернет-торговли, все ее показатели основываются на экспертных оценках или результатах различных, чаще всего социологических, исследований. В настоящее время население все больше включается в процесс интернет-торговли, что разнообразит экономическое поведение жителей нашей страны.

Заключение. Таким образом, экономическое поведение значимо в повседневной жизни россиян, анализ данных социологи- 
ческих исследований показывает наличие различных моделей экономического поведения, его особенности среди различных социальных групп населения современной России. Социологическое исследование, проведенное среди жителей города Шахты, показало не только значимость экономического поведения, но и позволило выявить ориентации респондентов в отношении тех или иных его типов. О рациональности потребительского поведения респондентов можно судить исходя из ориентированности населения на цены и величину собственного дохода. Интернетторговля, особенно в ситуации с коронавирусом COVID-19, и позиции интернет-практик в России будут укрепляться. Для развития интернет-торговли в России необходимо создать особые условия, исключающие чрезмерное регулирование. В условиях распространения коронавирусной инфекции в 2020 г. в российской экономике наибольший спад наблюдался в тех секторах, которые были ориентированы на потребительский спрос. И именно внутренний спрос, по прогнозам Министерства экономического развития Российской Федерации, останется основным источником роста ВВП в 2021-2023 гг.

\section{Литература}

1. Верховин В.И. Экономическое поведение: учебное пособие: в 2 частях. Ч. 1. Москва: РУДН, 2015.

2. Еременко С.Л. Экономическое поведение россиян как объект социологического анализа // Гуманитарные, социально-экономические и общественные науки. - 2014. - №2.

3. Земиов А. А. Экономическое поведение: первые исследования в СССР (начало 80-х - начало 90 гг. XX в.) // Проблемы учета и финансов. — 2017. - №4 (28).

4. Козлова М.А. Вклад Дж. М. Кейнса в анализ психологических мотивов экономического поведения // Вестник МГИМО. 2016. — №3 (48).

5. Белехова Г.В. Экономическое поведение населения: осмысление категории // Проблемы развития территории. - 2018. №5 (97).

6. Бушенева Ю.И. Экономическое поведение: обзор основных подходов // Царскосельские чтения. - 2015. - №XIX.
7. Социология: энциклопедия [Электронный ресурс] / Грицанов А. А., Абушенко В. Л., Евелькин Г.М., Соколова Г.Н., Т Терещенко О.В. - Минск: Интерпрессервис; Книжный Дом, 2003. - Режим доступа: https:// sociology_encyclopedy.academic.ru/1232/ (Дата обращения: 18.11.2020).

8. Магомедов И.Р. Факторный анализ экспорта нефти и нефтепродуктов из Российской Федерации в современных условиях// Российский внешнеэкономический вестник. - 2020. - №7. - С. 122.

9. Прогноз основных показателей социально-экономического развития РФ на 20202023 годы / А. Ведев, С. Дробышевский, А. Каукин и др. // Счетная палата Российской Федерации, Институт экономической политики им. Е. Т. Гайдара. - Москва, 2020. C. 4 .

10. Солдатова С. С., Пивкина К. Р. Экономическиепоследствия пандемии «COVID-19» для России // StudNet. - 2020. — №2. C. 260 .

11. Прогноз социально-экономического развития Российской Федерации на 2021 год и на плановый период 2022 и 2023 годов [Электронный ресурс]. - Режим доступа: https://www.economy.gov.ru/material/file/956c de638e96c25da7d978fe3424ad87/Prognoz.pdf (Дата обращения: 18.11.2020).

12. Еременко С. Л. Экономическое поведение россиян как объект социологического анализа // Гуманитарные, социально-экономические и общественные науки. - 2014. №2. - С. 98 .

13. Дулина Н. В., Моисеева Д. В., Ануфриева E. В., Парамонова В.А. Кредитная культура студентов как объект социологического анализа // Logos et Praxis. - 2019. - №1. - C. 85.

14. Гамукин В.В. Выявление особенностей сберегательного и кредитного поведения населения в регионах России // Экономика региона. - 2020. - Т. 16. - Вып. 3. C. 1003-1017.

15. Мониторинг: вклады, валюта, кредиты и покупки. Аналитический обзор. 11 ноября 2020 г. №4373. [Электронный ресурс]. - Режим доступа: https://old.wciom.ru/ index.php?id=236\&uid=10624 (Дата обращения: 18.11.2020).

16. Бочаров В. Ю., Гаврилюк Т. В. Модели экономического поведения рабочей молоде- 
жи // Вестник Санкт-Петербургского университета. Социология. - 2019. - Т. 12. Вып. 2. - С. 134.

\section{References}

1. Verhovin V.I. Jekonomicheskoe povedenie: uchebnoe posobie: $\mathrm{v} 2$ chastjah [Economic behavior: a textbook: in 2 parts]. Part 1. - Moscow: RUDN, 2015.

2. Eremenko S.L. Jekonomicheskoe povedenie rossijan kak obekt sociologicheskogo analiza [Economic behavior of Russians as an object of sociological analysis] // Gumanitarnye, social'no-jekonomicheskie i obshhestvennye nauki [Humanities, socio-economic and social sciences]. — 2014. — №2.

3. ZemcovA.A. Jekonomicheskoe povedenie: pervye issledovanija $\mathrm{v}$ SSSR (nachalo 80-h - nachalo 90 gg. XX v.) [Economic behavior: the first studies in the USSR (early 80's — early 90's). XX century)] // Problemy ucheta $\mathrm{i}$ finansov [Problems of accounting and finance]. — 2017. — №4 (28).

4. Kozlova M.A. Vklad Dzh. M. Kejnsa $\mathrm{v}$ analiz psihologicheskih motivov jekonomicheskogo povedenija [Keynes ${ }^{6}$ contribution to the analysis of psychological motives of economic behavior] // Vestnik MGIMO [MGIMO Bulletin]. — 2016. — №3 (48).

5. Belehova G. $V$. Jekonomicheskoe povedenie naselenija: osmyslenie kategorii [Economic behavior of the population: comprehension of the category] // Problemy razvitija territorii. 2018. — №5 (97).

6. Busheneva Ju. I. Jekonomicheskoe povedenie: obzor osnovnyh podhodov [Economic behavior: a review of basic approaches] // Carskosel'skie chtenija. - 2015. - №XIX.

7. Sociologija: jenciklopedija [Sociology: encyclopedia] [Jelektronnyj resurs] / Gricanov A.A., Abushenko V.L., Evel'kin G. M., Sokolova G. N., Tereshhenko O. V. - Minsk: Interpresservis; Knizhnyj Dom, 2003. — URL: https://sociology_encyclopedy.academic.ru/1232/ (Date accessed: 18.11.2020).

8. Magomedov I.R. Faktornyj analiz jeksporta nefti i nefteproduktov iz Rossijskoj Federacii $\mathrm{v}$ sovremennyh uslovijah [Factor analysis of the export of oil and petroleum products from the Russian Federation in modern conditions]// Rossijskij vneshnejekonomicheskij vestnik [Russian
Foreign Economic Bulletin]. — 2020. — №7. P. 122.

9. Prognoz osnovnyh pokazatelej social'nojekonomicheskogo razvitija RF na 2020-2023 gody [Forecast of the main indicators of socioeconomic development of the Russian Federation for 2020-2023] / A. Vedev, S. Drobyshevskij, A. Kaukin i dr. // Schetnaja palata Rossijskoj Federacii, Institut jekonomicheskoj politiki im. E. T. Gajdara [Accounts Chamber of the Russian Federation, Gaidar Institute of Economic Policy]. - Moscow, 2020. - P. 4.

10. Soldatova S.S., Pivkina K.R. Jekonomicheskie posledstvija pandemii «COVID-19» dlja Rossii [Economic consequences of the COVID-19 pandemic for Russia] // StudNet. 2020. — №2. - P. 260.

11. Prognoz social'no-jekonomicheskogo razvitija Rossijskoj Federacii na 2021 god i na planovyj period 2022 i 2023 godov [Forecast of socio-economic development of the Russian Federation for 2021 and for the planning period of 2022 and 2023] [Jelektronnyj resurs]. — URL: https://www.economy. gov.ru/material/file/956cde638e $96 \mathrm{c} 25 \mathrm{da} 7 \mathrm{~d} 9$ 78fe3424ad87/Prognoz.pdf (Date accessed: 18.11.2020).

12. Eremenko S.L. Jekonomicheskoe povedenie rossijan kak obekt sociologicheskogo analiza [Economic behavior of Russians as an object of sociological analysis] // Gumanitarnye, social'no-jekonomicheskie i obshhestvennye nauki [Humanities, socio-economic and social sciences]. - 2014. - №2. - P. 98.

13. Dulina N.V., Moiseeva D.V., Anufrieva E.V., Paramonova V.A. Kreditnaja kul'tura studentov kak obekt sociologicheskogo analiza [Credit culture of students as an object of sociological analysis] // Logos et Praxis. - 2019. №1. - P. 85.

14. Gamukin V.V. Vyjavlenie osobennostej sberegatel'nogo i kreditnogo povedenija naselenija $\mathrm{v}$ regionah Rossii [Identification of features of savings and credit behavior of the population in the regions of Russia] // Jekonomika regiona [The economy of the region]. - 2020. Vol. 16. - Issue 3. - Pp. 1003-1017.

15. Monitoring: vklady, valjuta, kredity i pokupki. Analiticheskij obzor. 11 nojabrja 2020 g. [Monitoring: deposits, currency, loans and purchases. Analytical review. November 11, 2020]. №4373. [Jelektronnyj resurs]. — URL: https:// 
old.wciom.ru/index.php?id=236\&uid=10624 (Date accessed: 18.11.2020).

16. Bocharov V. Ju., Gavriljuk T.V. Modeli jekonomicheskogo povedenija rabochej molo- dezhi [Models of economic behavior of working youth] // Vestnik Sankt-Peterburgskogo universiteta. Sociologija. - 2019. — Vol. 12. - Issue 2. - P. 134.
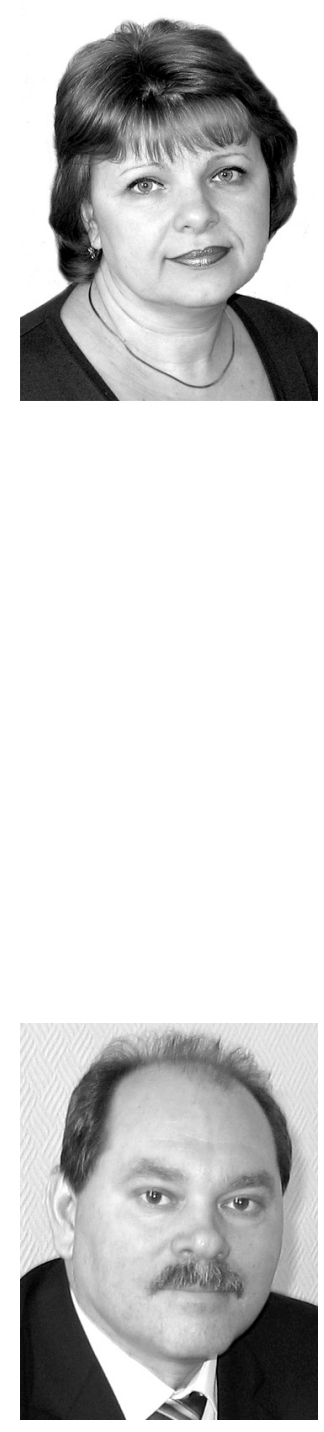

Барсукова Светлана Викторовна - кандидат социологических наук, доцент кафедры «Экономика и управление» Шахтинского автодорожного института (филиала) ЮРГПУ (НПИ) им. М.И. Платова. Автор работ по проблемам семьи, бедности и неравенства в современной России.

Barsukova Svetlana Viktorovna - Candidate of Sociological Sciences, Associate Professor at «Economy and management» Department, Shakhty road Institute (branch), Platov South Russian State Polytechnic University (NPI). Author of numerous works on actual problems of family relations, poverty and social inequality in nowadays Russia.

346500, г. Шахты, пл. Ленина, 1

1 Lenina sq., 346500, Shakhty, Russia

E-mail: svetlana_vbar@mail.ru

Барсуков Сергей Михайлович - кандидат исторических наук, доцент кафедры «Экономика и управление» Шахтинского автодорожного института (филиала) ЮРГПУ (НПИ) им. М.И. Платова. Автор работ по проблемам семьи, молодежи, политической социологии, государственного и муниципального управления.

Barsukov Sergey Mikhajlovich - Candidate of Historical Sciences, Associate Professor at «Economy and management» Department, Shakhty road Institute (branch), Platov South Russian State Polytechnic University (NPI). Author of works on problems of a family, youth, political sociology, public and municipal administration.

346500, г. Шахты, пл. Ленина, 1

1 Lenina sq., 346500, Shakhty, Russia

E-mail: sergei-mb@mail.ru 


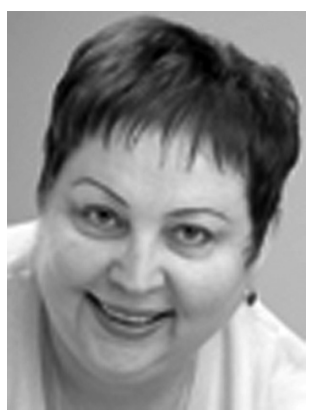

Ткачева Ольга Анатольевна - кандидат технических наук, доцент, заведующая кафедрой «Экономика и управление» Шахтинского автодорожного института (филиала) Южно-Российского государственного политехнического университета (НПИ) имени М. И. Платова.

Tkacheva Olga Anatolyevna - Candidate of Engineering Sciences, Associate Professor, Head of the Department «Economics and management», Shakhty road Institute (branch), Platov South Russian State Polytechnic University (NPI).

346500, г. Шахты, пл. Ленина, 1

1 Lenina sq., 346500, Shakhty, Russia

E-mail: oa.tkachova@mail.ru 